\title{
ENTREVISTA
}

\section{SECRETÁRIO-GERAL DÁ O TOM DA REFORMA: \\ Administração Direta de novo fortalecida}

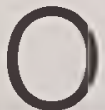

Secretário-Geral SEDAP, Gileno

Fernandes Marcelino, coordenou os seminários internos em que se envolveram, ao longo dos meses de janeiro e fevereiro, todos os executivos da Secretaria de Administracão Pública da Presidência da República, além dos assessores de alto nivel. os quais, sob a presidência e liderança do Ministro Aluizio Alves, produziram o Plano de Trabalho da $S E D A P$, que é publicado, em resumo, nesse número. Foi a primeira tentativa, com pleno êxito, de uma mudanca participativa, de baixo para cima, no âmbito do governo, $e$ seu objetivo era iniciar o processo de transformacào do antigo DASP na nova SEDAP. Com um plano de trabalho e um novo organograma, moderno e tecnicamente bem concebido, o SEDAP tem condicóes de levar adiante uma das metas consideradas prioritárias da Nova República: a racionalização do serviço público brasileiro em niveis de uma verdadeira reforma administrativa que mude definitivamente o corpo e a alma da velha e emperrada máquina administrativa federal.

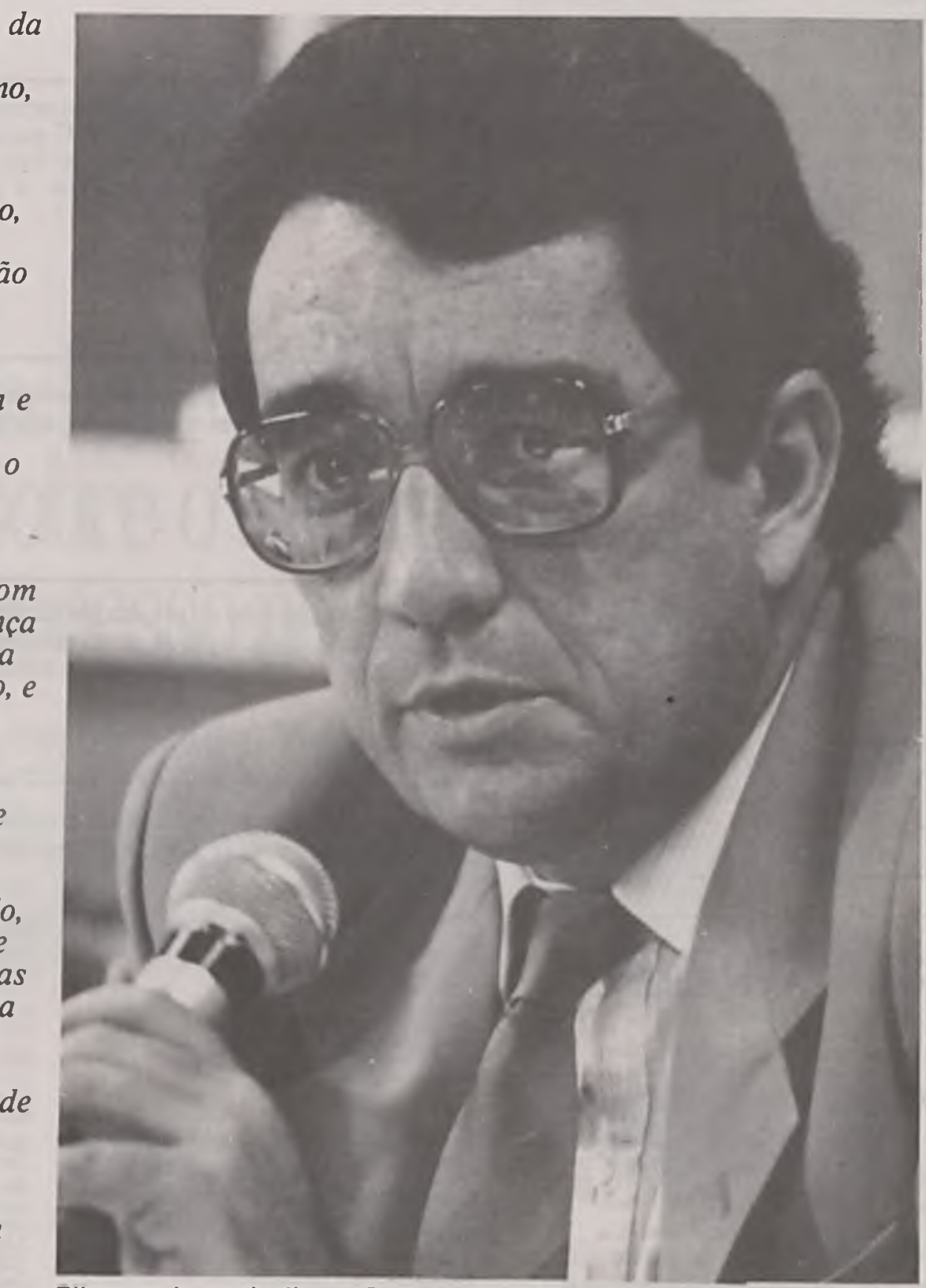

Glleno pede ampla discussāo sobre a administraçao pública 
ENTREVISTA

$P$ - Acaba de ser desenvolvido o planejamento estratégico da SEDAP para 87. Qual foi o sentido dessa relomada de esforcos da SEDAP?

$\mathrm{R}$ - Há todo um sentido histórico nesse processo. $O$ que estamos fazendo é a tentativa de transformação do DASP, com sua herança ultrapassada, pela SEDAP, uma agéncia de reforma e modernização do serviço publico. Gostaria de começar fazendo um pequeno histórico e diagnóstico da função administrativa do Governo Federal, que na verdade existiu de maneira sistemática a partir da criação do DASP, ainda no periodo do Estado-Novo, com o Presidente Getúlio Vargas. Foi em 1937 que o DASP trouxe para nosso Pais aqueles principios de administração até então pretensiosamente chamados de "cientificos". O DASP, na época, era, na verdade, um órgão moderno e racionalizador. Foi através dele que se falou pela primeira vez em carreira no serviço público e foi nele que pela vez primeira se viabilizou um esforco de orçamentação do Governo Federal. Mas o DASP era um produto do EstadoNovo, portanto do periodo autoritário, e esse fato iria estigmatizar.

$P$ - Isso tudo ocorreu nos primórdios. E quando foique se iniciaram as distorcōes que hoje explodiram na administração püblica?

R-Por volta de 1940, Luiz Simōes Lopes, e sua equipe de colahoradores do antigo DASP, deram inicio ao processo de implantação do então moderno modelo administrativo brasileiro que buscava a eficiència. Tudo ia muito bem, com a carreira do serviço público regida por sistema de mérito, carreira acesso, concursos públicos etc. e um modelo que prestigiava a administraçăo direta. Mas na queda de Getúlio, em 1945. no curto interregno da presidència de José Linhares, foi quebrado o sistema de mérito, com a contratação. para o Governo Federal, dos primeiros funcionários extranumerarios, que viriam a ser os precursores dos tabelistas especiais dos últimos tempos. Dai para a frente, acumularam-se as distorçōes.

$P$ - O Sr. situa as distorfóes como produtos da era desenvolvimentista que caracterizou os anos 50. O de-

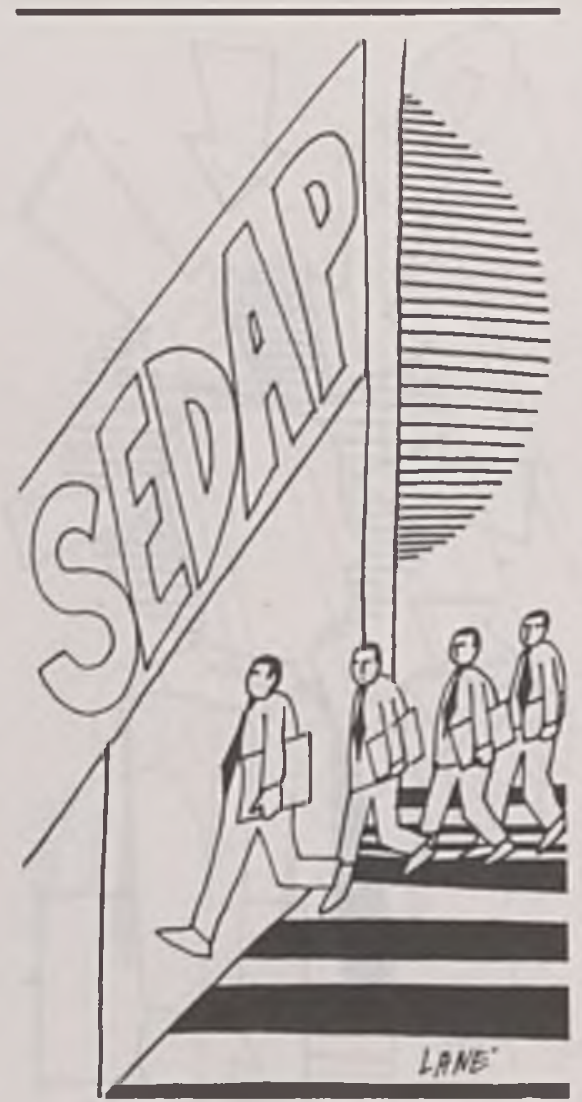

$O$ sistema de mérito no acesso ao serviço público foi quebrado pela primeira vez em 1946, após a queda de Getúlio Vargas, com a criação dos extranumerários, que foram os precursores dos tabelistas especiais de agora.

senvolvimento trouxe consigo o germe da ineficiência pública?

$\mathbf{R}$ - Só quero ponderar que, no começo do século. existiam na esfera do Governo Federal de 8 a 10 entidades. Nos anos 50 , passaram a 80 entidades, que se multiplicaram apos - Decreto-Lei no $200 \mathrm{~cm} 1967$. Ja em 81 . cram cerca de 581 entidades, entre fundaçoes, empresas puhlicas, sociedades de economia mista c autarquia. O que houve? Sohretudo na decada de 60 . houve a implanta- cão de um novo modelo administrativo que se chamava "development administration". uma administração voltada para o desenvolvimento económico do País. JK, com seu plano de metas arrojado, precisou se apoiar em grupos executivos ágeis para construir Brasilia, implantar rodovias etc.. Foi privilegiada a administração indireta, que explodiu diante da lentidão burocrática da administração direta, que foi ficando para trás. De repente as raizes da administração direta comecaram a ser arrancadas pela velocidade do vento das mudanças: foram sendo marginalizados os planos de carreira. de cargos e remuneração do serviço público, em nome das tabelas especiais e das concessões extraordinarias. Toda a montagem estruturaria do antigo DASP e as esquematizaçōes cientificas da década de 40 foram dando lugar a uma pletora de tabelas especiais que chegaram a 106. Hoje, apenas $6 \%$ do universo do funcionalismo publico são regidos pelos antigos critérios do DASP, cerca de 125 mil estatutários.

P-Mas essa não è uma tendência do Estado moderno para vencer a excessiva burocratizaçāo?

$\mathrm{R}$ - Nem tanto, nem tampouco. Criou-se uma dicotomia entre um Estado moderno e eficiente representado pela administração indireta e um Estado burocrático e ineficiente representado pela administraçāo direta. A adminstração direta è a cabeça do Estado, pois é a que assegura o "ius imperii", o poder de policia e decisão de que o governo se vale para instrumentar sua presença como fator de equilibrio institucional. $O$ espirito atual do nosso processo de reforma é exatamente o de repor as raizes em seus lugares, instrumentando o Estado para que volte a ser eficiente e ágil nas duas dimensōes, e não uma estrutura burocratizada e burocratizante. Reconheço que o Estado moderno é o da administração indireta, mas a parte não poderá jamais esfacelar o todo, pois na cabeça, isto é, na administração direta e que reside o poder institucionalizado, e não nos seus membros. hoje representados pelas entidades da chamada administração indireta.

$P$ - Entào, quais serāo os principios dessa grande volta às raizes?

R-Primeiramente, o Ministro Aluizio Alves, quando chegou ao 


\section{ENTREVISTA}

antigo Ministério da Administração, hoje Secretaria de Administração da Presidência da República, lá não encontrou mais que o antigo DASP. Encontrou, também, 106 tabelas especiais com cerca de 360 diferentes niveis de remuneração. $\mathrm{O}$ número de tabelistas especiais era de 100 mil. Hoje essas tabelas desapareceram, já estào uniticadas. Esse foi o começo da volta às raizes, o que significa o retorno à moralidade do serviço público no que toca à igualdade de oportunidades de seu pessoal, como tambem igualdade no acesso, na promoção e na ascensão funcional pelo mérito. $\mathrm{O}$ acesso à carreira pública voltando a ser franqueado apenas por concurso, e com o funcionário tendo a chance de treinamento e reciclagem para galgar posiçōes superiores na carreira, podendo chegar à cúpula de sua repartição através de provas internas. Isso tudo e o que está acontecendo agora.

$P$ - E na reforma administrativa do governo Sarney e da Nova República: que sentido fundamental o Sr. destaca?

R-A funçào de planejamento administrativo, que naao havia, no governo federal, e que nos atos da reforma administrativa baixado pelo presidente Sarney, em setembro de 1986, foi institucionalizada. Essa foi, ao meu ver, a grande contribuiçào para a modernização da chamada máquina administrativa. Tudo isso acontece com a democratizaçào e pela democratizaçào do Pais. Lembre-se que o antigo DASP foi perdendo força com a redemocratizaçào de 1946. Esperamos que essa função nova, entregue à SEDAP. seja o grande instrumento da viahilização do processo de Reforma Administrativa no Pais, nos próximos anos. As funçōes básicas de pensar o governo, há anos, vèm sendo exercidas, dentro do governo, por um tripé: a função-planejamento, exercida inicialmente atraves do Ministerio do Planejamento, mais tarde Secretaria de Planejamento da Presidência da República, e que executava seus planos através do Instituto de Planejamento do IPEA. A segunda peça era naturalmente a função-orçamento, que já tinha, nos idos de 40 e 50 , como dissemos no inicio dessa entrevista, pertencido ao proprio DASP, e que foi transferida, inicialmente, para

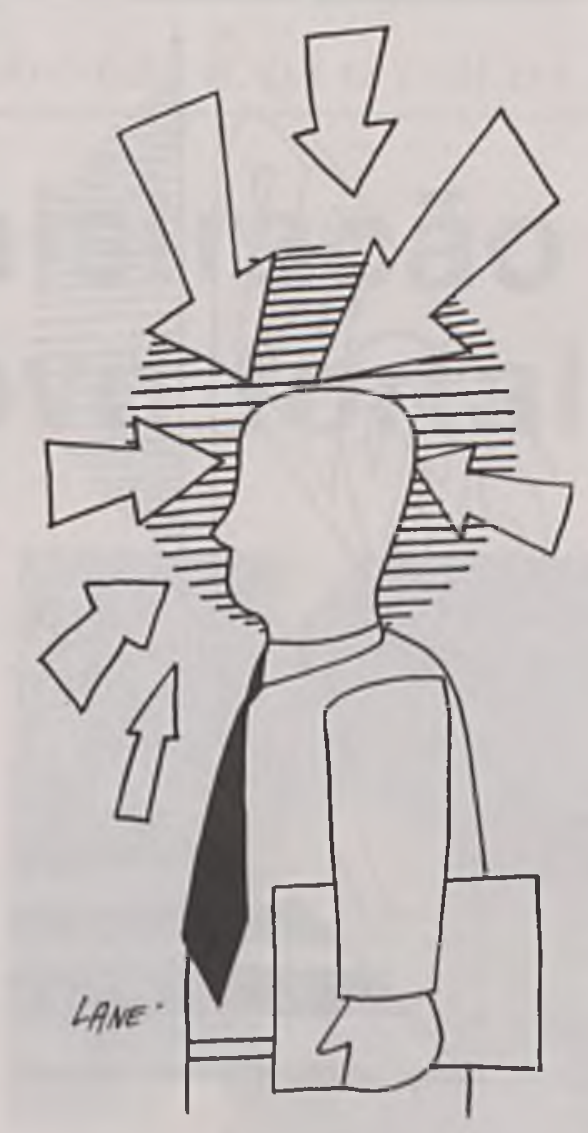

$O$ desenvolvimento dos anos 50 e 60 trouxe uma reforma da administração pública, com ênfase na criação de empresas estatais, companhias mistas $e$ fundaçōes. Ocorreu o "boom" do sistema indireto, invertendo a predominância da administração direta.

- Ministério da Fazenda, e depois para o Ministério do Planejamento, a SEPLAN, que passou a exercer aquela função orçamentária atraves do Instituto Nacional de Orçamento da Secretaria de Orçamento e Financas. A terceira peça nesse tripe, e que nunca foi implantada, é exatamente a função de modernização administrativa: a idéia era a de que uma Secretaria de Modernizacão Administrati- va, que existia na própria SEPLAN, especialmente a partir de 1972, deveria ir adaptando e adequando a chamada estrutura governamental aos novos tempos administrativos.

Mas infelizmente isso nunca aconteceu, pois a SEMOR e, em conseqüência, a sua função precipua, ficaram sempre a reboque do planejamento econômico exercido na SEPLAN. Faltava-lhe prestigio, reconhecimento dos demais setores da administração pública federal, além de uma ação mais agressiva. E naturalmente a SEMOR, que não era prioritária, não tinha recursos humanos, materiais e financeiros, para cumprir o seu objetivo.

\section{$P-E$ agora, existe?}

$\mathrm{R}$ - Passa a existir, e não é fácil o inicio dessa existência. Faltava ao governo, sobretudo, uma especie de mecanismo sistemático de implementação, coordenação e avaliação das atividades de reforma administrativa, e de modernização dos órgãos da administração pública. Existe agora, com a SEDAP. Havia pouca coordenação, e, ao contrário, abundava dissociação das atividades de planejamento, modernização e de recursos humanos a nivel de governo. Existe agora, com o GERAP, o Grupo Executivo da Reforma Administrativa integrado pelos Ministros da Administração, que è seu Presidente, do Gabinete Civil, da SEPLAN, da Fazenda e do Trabalho. Havia, ainda, uma ação poı:co integrada, desde 1979 , quando existiam, em très areas distintas, a SEMOR, o DASP e o Programa Nacional de Desburocratizaçăo, que mais tarde viria a se transformar em Ministério. Integraram-se todos, agora, num só órgão, a SEDAP. O antigo DASP foi absorvido pela moderna Secretaria de Administração da Presidência da República, cujo planejamento estratégico acaba de ser desenvolvido em reuniōes com todos os integrantes de nosso sistema, discussōes francas e abertas, lideradas pelo Ministro Aluizio Alves, do qual saiu um primeiro documento, cujo resumo este número da REVISTA DO SERVICO PUBLICO está justamente publicando.

P-Então, podemos confiar em que a reforma administrativa agora sai? 


\section{ENTREVISTA}

$\mathrm{R}$ - Já saiu. Desde setembro do ano passado, quando os atos baixados pelo Sr. Presidente da República, instituindo diversos programas e projetos para a execução da reforma, já nos deram a instrumentação legal. A instrumentaçāo politica está sendo exemplarmente conduzida pelo $\mathrm{Mi}$ nistro Aluizio Alves e pelos demais ministros participantes do GERAP, os quais ja aprovaram diversos planos de reformulação de órgãos públicos. Mas, logo no começo do ano, uma prova cabal de que a reforma administrativa está andando a passos largos, foi o restabelecimento da ascensão funcional, que, depois de dois anos de suspensão, voltou a incorporar requisitos como merecimento, cumprimento dos intersticios necessários, existência de vaga e de verbas. Esse restabelecimento veio a tempo para se dar início ao novo plano de carreiras do funcionalismo, tema a que o Ministro Aluizio Alves se entrega com verdadeira devoção, como mostra em seu artigo que é publicado nessa edição da REVISTA DO SERVIÇO PÚBLICO. Outro grande passo será o envio, ao GERAP. pelos ministérios, dos planos de reformulação administrativa interna. Já nos poucos meses de sua existência, o GERAP, de que somos coordenador executivo, criado a 3 de setembro de 1986 para promover as medidas necessárias à implantação da reforma da administração pública federal, de acordo com o decreto n: 93.212, ja aprovou a transformaçào do IBC e da SUDEVHEA em conselhos, diminuindo a ação do Estado no que é de vocação do setor privado. Havia excesso de funcionários, tanto em um quanto em outro órgào, mais de $3 \mathrm{mil}$ ao todo, e o GERAP decidiu colocá-los à disposiçào da SEDAP para que sejam redistribuidos para outros órgãos que reclamam de falta de quadros, entre eles os novos ministerios.

\section{$P-E$ os demais alos da reforma administrativa?}

R - A SEDAP está desenvolvendo uma nova politica de recursos humanos. A FUNCEP será a cabeça do sistema de reflexão e desenvolvimento de estudos e projetos para a administração pública. A ENAP. Escola Nacional de Administração Pública, já está cm regime final de implantação e se prepara para seu primeiro vestibular no àmbito da re-

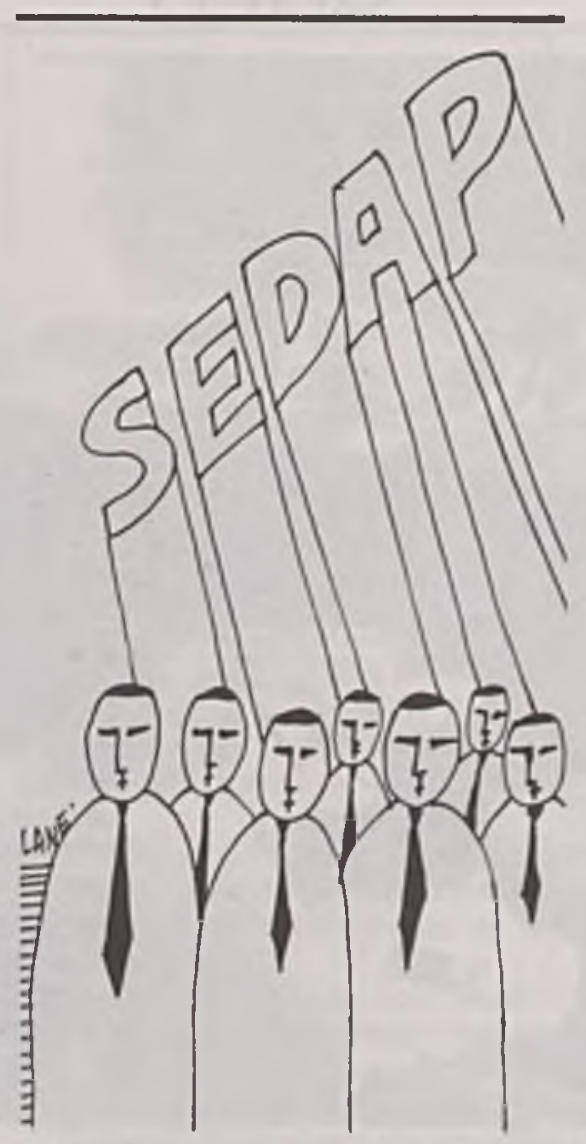

Todo o processo que ativamos agora tem $o$ sentido de fortalecer a administração direta, dando-lhe novos instrumentos para recuperar seu poder de gestão e a possibilidade de um - planejamento geral de suas atividades.

ciclagem de quadros de alto nivel da administração pública. O CEDAM, - Centro de Desenvolvimento da Administração Pública, já está se articulando para planejar, promover, coordenar e avaliar as atividades de treinamento dos servidores civis, para descobrir novas técnicas e possibilidade de acōes. Já estão em plena ação os Serviços juridicos integrados do governo na Advocacia Consultiva da União, que está centra- lizando e coordenando todos os atos juridicos do governo. Do mesmo modo, está em franca ação o controle e fiscalização das atividades da administração pessoal pelo SIPEC. Sistema de Pessoal Civil da Administração Pública, que funciona como uma auditoria permanente nos órgãos federais. Um projeto importante, o $\mathrm{Ca}$ dastro Nacional do Pessoal Civil da Administração direta e indireta, está em pleno desenvolvimento, e o governo vai enviar ao congresso o anteprojeto do Estatuto do Servidor Público. Pretendemos dar uma colaboração viva e interessada da SEDAP junto aos Srs. constituintes, para que na futura carta constitucional sejam defendidos os pontos essenciais da reformulação administrativa, notadamente os planos de carreira e a dignificação do servidor público. Atualmente, a SEDAP, juntamente com os ministerios interessados, já implantou a reformulaçào do Itamaraty, do IBC. SUDEVHEA e se prepara para reformular a do Ministério da Cultura, dos Transportes e implantar reformas no Incra e no Ministério da Saúde. No geral, serão reduzidos órgãos, divisōes e departamentos que foram criados para elevar salarios de funcionarios. Estamos revendo as gratificaçōes. Uma nova lei de licitaçōes públicas, essencial para desemperrar os processos licitatórios, já foi decretada.

P-Para finalizar: a reforma também pegou os estados, com os governadores empossados?

$\mathrm{R}$ - Basta ver as primeiras declaraçōes publicas dos novos governadores, após as posses a 15 de março nos governos estaduais. Todos estão empenhados em dar ao problema da eficiència e eficácia da máquina administrativa sua primeira prioridade. Somente esse empenho dos governadores justificaria que o governo federal tivesse plantado a primeira semente, para se antecipar e dar o exemplo a Federação. deflagrando sua propria reforma administrativa. Estamos no caminho certo. União e Estados, e certamente logo os municipios, onde vivemos nos, os cidadãos, seguirão o mesmo exemplo. Com isso, os très niveis do govemo prestarào melhores e maiores serviços à sociedade brasileira, finalidade para a qual existem e estão sendo transformados. 